54,3, pp. 871-879, Warsaw 2016

DOI: $10.15632 /$ jtam-pl.54.3.871

\title{
NUMERICAL AND FIELD INVESTIGATIONS OF TRACK DYNAMIC BEHAVIOR CAUSED BY LIGHT AND HEAVY RAILWAY VEHICLES
}

\author{
Jabbar Ali Zakeri, Seyed Ali Mosayebi, Morteza Esmaeili \\ School of Railway Engineering, The Center of Excellence in Railway Transportation, Iran University of Science \\ and Technology, Tehran, Iran \\ e-mail: zakeri@iust.ac.ir; mosayebi@iust.ac.ir; m_esmaeili@iust.ac.ir
}

\begin{abstract}
Dynamic behavior of a track-train system is a function of axle loads and support stiffness because of non-linear supports. Therefore, it is expected that the support stiffness affects the behavior of the railway track during passing of a light or heavy car body. Since the effects of axle loads caused by light and heavy railway vehicles and support stiffness of ballasted railway tracks due to passing railway vehicles have not been studied adequately, therefore the present study focused on this issue. For this purpose, this issue was first investigated by passing a light and heavy car body including bogies with three axle loads as field tests. Then, numerical analyses of the railway track caused by the passing of these railway vehicles were studied, and the numerical results were compared with the field results. There was a good agreement between the values of field responses and numerical analyses. Subsequently, a series of sensitivity analyses on effects of the axle loads caused by light or heavy loading and support conditions was done on the ballasted railway track. The results indicated that the maximum vertical displacements increased by axle loads, increased sleeper distances and decreases support stiffness. Finally, equations of track behavior based on support stiffness and axle loads were derived.
\end{abstract}

Keywords: numerical and field investigation, railway track, track dynamics, railway vehicles

\section{Introduction}

In order to understand the mechanism of railway tracks and reduction of maintenance costs, the dynamic behavior of the railway track should be investigated. Since it was difficult to measure responses of the railway track directly in field, therefore models of railway tracks were investigated usually. The available technical literature indicated that different models and methods were presented for the analysis of railway tracks by various researchers. Usually, numerical models for analyzing the railway track are: one-dimensional model of a railway including lumped masses, two-dimensional model of a track including beam on an elastic foundation with continuous supports or discrete supports. There are many researchers in the field of modeling and dynamic analysis of railway tracks. In these studies, several models have been proposed for investigating the railway track and its components. Generally, the research fields of these researchers could be divided into three categories: dynamic analysis of railway tracks, simulation of the vehicle and railway track, and train-track interaction. Some of the most prominent researchers who studied these fields are: Cai (1992), Zhai and Sun (1994), Knothe (1995), Zhai and Cai (1997), Fryba (1999), Zakeri (2000), Popp et al. (2003), Zakeri and Xia (2008), Bogacz and Czyczuła (2008), Dahlberg (2010) and Zakeri and Ghorbani (2011). Among the most important parameters in the analysis of railway tracks, axle loads of railway vehicles and support conditions of ballasted railway tracks could be pointed out. Some of researchers worked in the field of the effects of stiffness of railway track components. For example, Kerr (2003) investigated the behavior of the rail on elastic supports due to moving load. Zhai et al. (2004) studied vibrations of the railway 
ballast in tracks. Witt (2008) studied the behavior of under sleeper pads in railway tracks. Puzavac et al. (2012) investigated vertical stiffness of the railway track due to passing loads. Zakeri and Abbasi (2012) investigated stiffness of the railway track in desert areas. Also, Esmaeili et al. (2014) studied the sand fouled ballast on train induced vibrations. In the mentioned studies and the available technical literature, the effects of a passing light railway vehicle (Draisine) and a heavy railway vehicle including bogies with three axle loads on ballasted railway tracks have not been studied adequately. Also considering that the behavior of the railway track support is nonlinear and depends on train loads, the effects of various passing train loads including the light and heavy railway vehicles have been studied in this paper. Therefore, the simulation of light and heavy car bodies has been explained in this paper. Afterward, a series of field tests by using light or heavy loading was done for validating the numerical analyses. After validation and in continuation, the effects of axle loads caused by light and heavy railway vehicles and support stiffness of the railway track were studied. Finally, equations of the track behavior based on the support stiffness and then the axle loads were derived.

\section{Modeling of the railway track}

In modeling of the railway track with the concept of railway tracks on a viscoelastic foundation, two models can be considered. These are: (a) railway track with one layer including a continuous rail, (b) railway track with two layers including the rail and sleepers. In Fig. 1, the railway track with two layers is presented. The first layer is the rail as a continuous support and the second layer are sleepers as discrete supports.

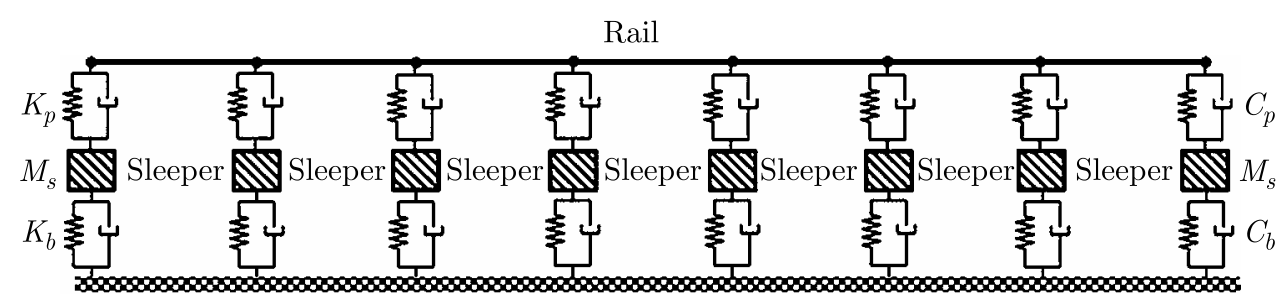

Fig. 1. Railway track with two layers (rail and sleeper)

As can be observed from Fig. 1, the sleepers are modeled as a series of lumped masses. In this figure, $K_{p}$ and $K_{b}$ are pad and support stiffnesses, respectively. Figure 2 shows the rail and sleeper in the model of the railway track with two layers.

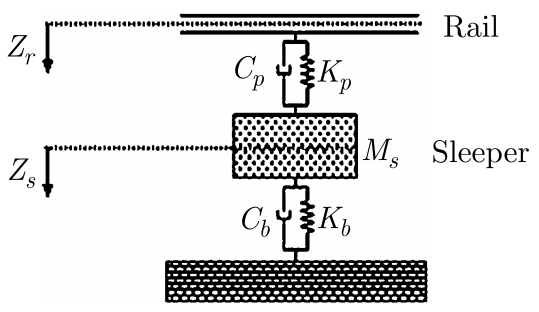

Fig. 2. Rail and sleeper in the railway track model

By using the finite element method, the rail is divided into several elements, and the matrix of each element is derived. Then the total matrix of the rail is derived by assembling all rail elements. In each element of the rail, vertical stiffness of rail pads is considered in beam joints. Also, stiffness, damping and mass matrix of the railway track with two layers can be considered as a submatrix of the whole system (Zakeri, 2000). 


\section{Modeling of railway vehicles}

In this Section, the passing railway vehicles including light and heavy railway car bodies are simulated. In this regard and by using the finite element method, the equations of motion of all components of the light and heavy railway vehicles are derived and their matrices are formed. Then by assembling the matrices of railway vehicles and tracks, the derived equation is solved with available numerical methods. Next, the models of light and heavy railway vehicles are presented.

\subsection{Heavy railway vehicle}

In order to model a rail vehicle for heavy loading, a car body including bogies with three axle loads is considered, see Fig. 3 .

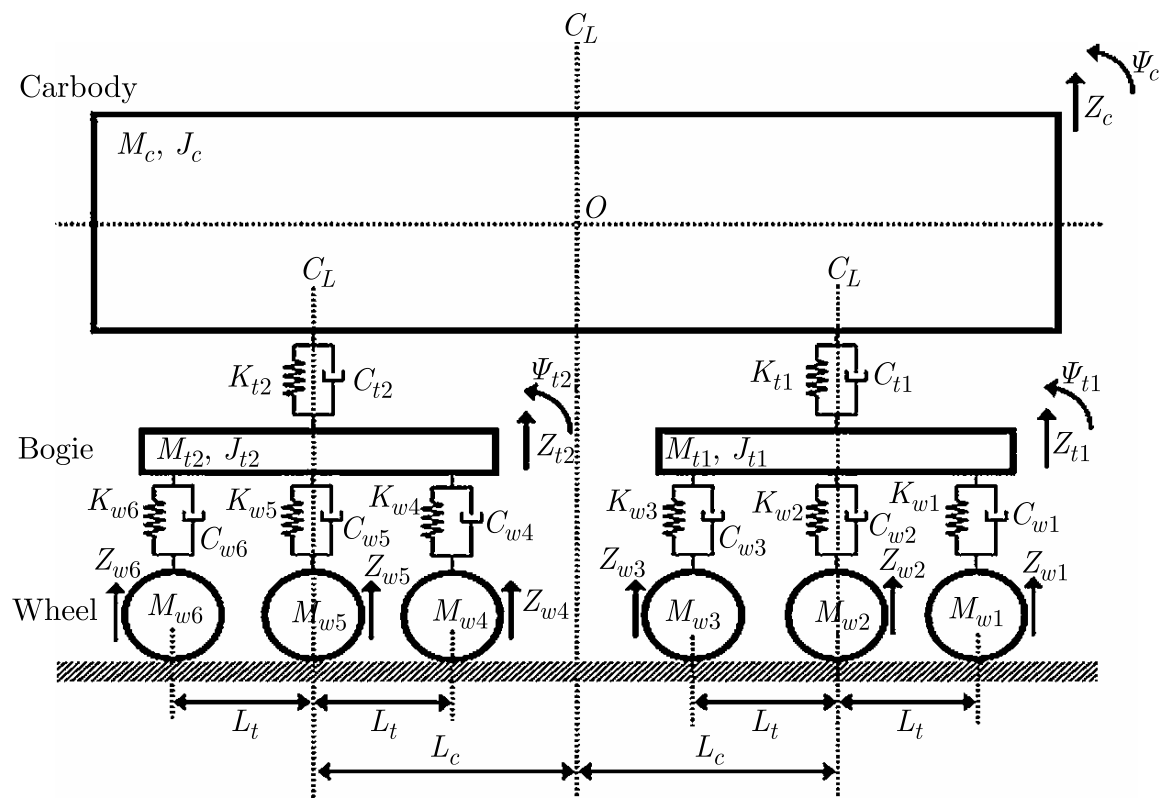

Fig. 3. Heavy railway car body including bogies with three axle loads

In Fig. 3, $L_{c}$ and $L_{t}$ are halves of the bogies and wheels axes, respectively. In this figure, $M_{c}$ is car body mass, $M_{t}$ - bogie mass, $M_{w}$ - wheel mass, $J_{c}$ - car body rotational inertia and $J_{t}$ is bogie rotational inertia. As can be seen in Fig. 3, the car body has bogies with three axle loads. $C_{w}, K_{w}, C_{t}$ and $K_{t}$ are primary and secondary suspension damping and stiffness, respectively. So, $Z c$ is the vertical displacement of the car body, $\psi_{c}$ - rotation of the car body, $Z_{t}$ - vertical displacement of the bogie, $\psi_{t}$ - rotation of the bogie and $Z_{w}$ is vertical displacement of the wheel.

\subsection{Light railway vehicle}

Also, in order to model a railway vehicle for ight loading, a draisine with two axle loads is considered as shown in Fig. 4.

In Fig. $4, M_{D}$ and $J_{D}$ are mass and rotational inertia of the draisine, respectively. $K_{w}$ and $C_{w}$ are suspension system damping and stiffness, respectively. Also, $Z_{D}$ is the vertical displacement of the draisine, $\psi_{D}$ - its rotation and $Z_{w}$ is the vertical displacement of the wheel. In the following, the procedure of field tests caused by a passing light draisine and a heavy car body is presented. 


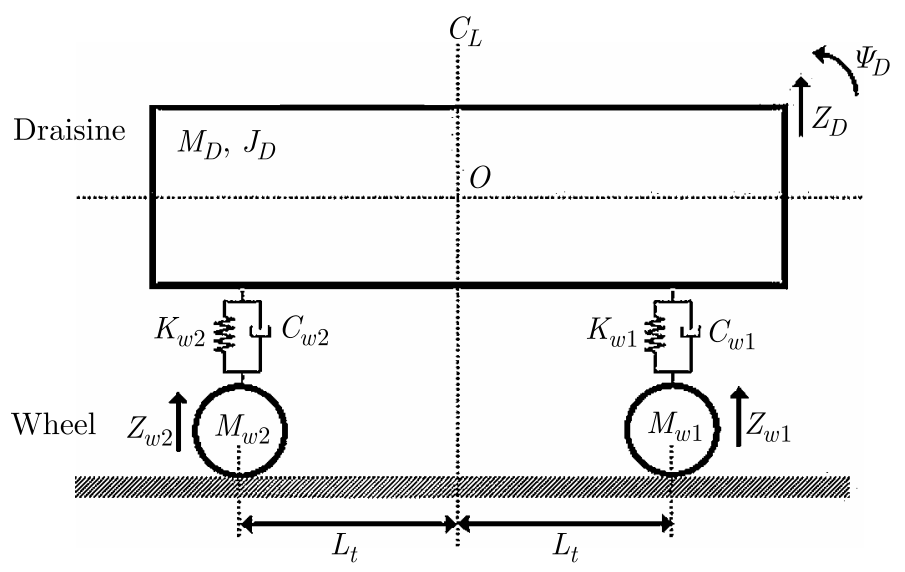

Fig. 4. Light railway draisine with two axle loads

\section{Field tests}

For investigating the behavior of a ballasted railway track in field, a railway track was selected in Iran. In order to obtain time histories of the vertical displacement of the railway track in field tests, two types of railway vehicles including light and heavy railway vehicles were utilized. For applying light loading, a draisine with two axle loads was used. Specifications of that draisine were: total weight 4 tons, axle load 2 tons, wheel load 1 ton, length $4 \mathrm{~m}$ and vehicle speed $30 \mathrm{~km} / \mathrm{h}$. Also, locomotive GT26CW was used to apply heavy loading. Specifications of the locomotive were: total weight 110 tons, axle load 18.3 tons, wheel load 9.2 tons, length $18 \mathrm{~m}$ and vehicle speed $30 \mathrm{~km} / \mathrm{h}$ (Zakeri and Abbasi, 2012). Figure 5 indicates the passing of the light and heavy railway vehicles.

(a)

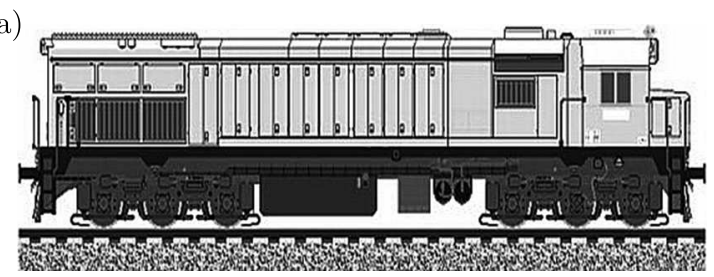

(b)

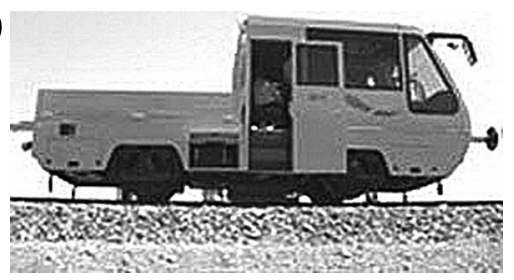

Fig. 5. Railway vehicles for field tests; (a) GT26CW locomotive including bogies with three axle loads, (b) draisine with two axle loads

For measuring the vertical displacement of the railway track caused by the rail vehicles, linear variable differential transformers (LVDT's) located on sleepers were utilized (Fig. 6).

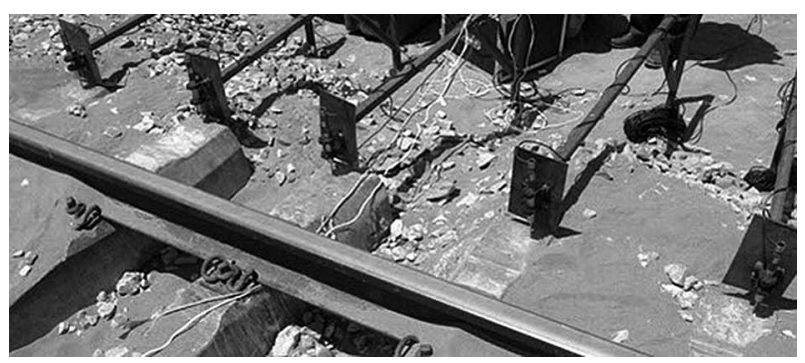

Fig. 6. Linear variable differential transformer (LVDT) for measuring the vertical displacement of the railway track

In next Section, results of numerical analyses are compared and validated with the responses from field tests. 


\section{Validation of the railway model}

In order to validate the results of numerical analyses, they have been compared and validated with the results of field tests. Figure 7 shows numerical and field vertical displacement time histories of the railway track caused by the car bodies.

(a)

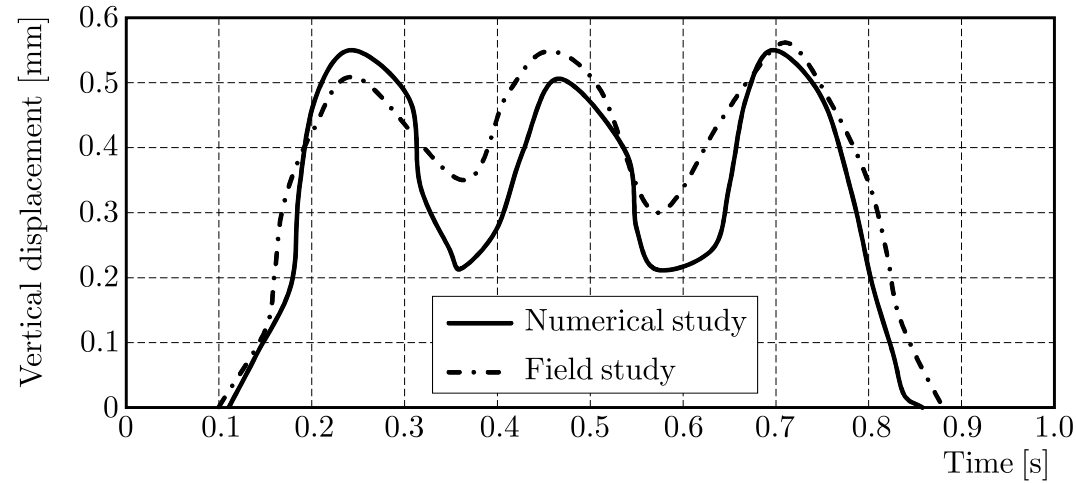

(b)

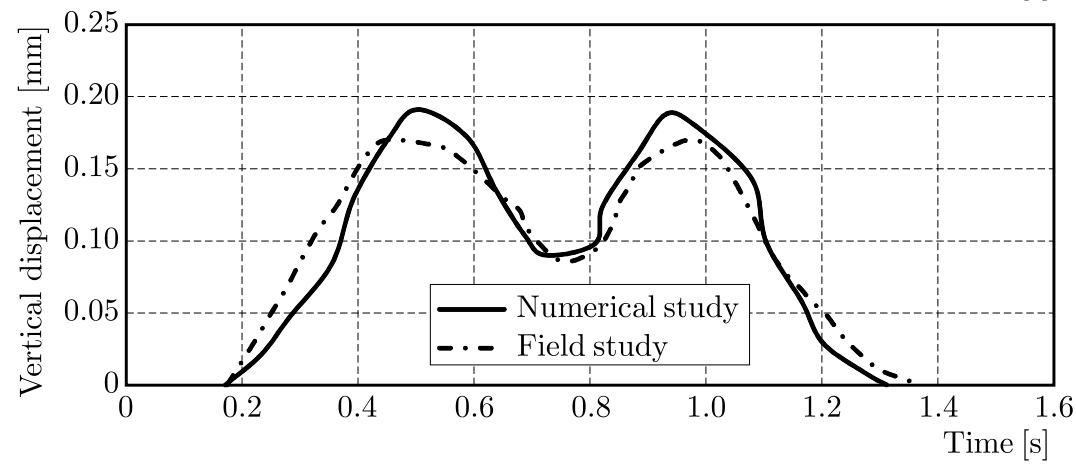

Fig. 7. Vertical displacement time histories of the railway track caused by railway vehicles;

(a) heavy vehicle, (b) light vehicle

By observing and comparing vertical displacement time histories of the railway track caused by passing railway vehicles and those obtained from numerical simulation and field studies, two important points could be extracted. Firstly, the range of field responses is in a good agreement with the values of numerical analyses. Secondly, the trend of field responses shows a good agreement with the numerical analyses. Hence, it could be concluded that the modeling and numerical analyses of the railway track caused by a light draisine and a heavy car body have been done correctly. In the next Section, equations of the railway track according to the support stiffness and axle loads are derived.

\section{Track behavior versus support stiffness}

In this Section, effects of axle loads of light and heavy car bodies are investigated in terms of the behavior of a ballasted railway track. Figure 8 indicates a sample of the vertical displacement time history of the railway track due to passing of light and heavy railway vehicles.

As can be observed in Fig. 8, the vertical displacement time history of the railway track has two and six peaks due to passing of a light draisine and a heavy car body, respectively. Figure 9 shows the ratio of the maximum vertical displacement with respect to the light and heavy axle loads $[\mathrm{mm} / \mathrm{ton}]$ against the support stiffness $[\mathrm{MN} / \mathrm{m}]$ for various distances between the sleepers.

As can be seen in Fig. 9, the maximum vertical displacement per unit axle load is constant for higher support stiffness. The maximum vertical displacements decrease for growing axle loads. Also, the increase of the sleeper distances and decreasing of the support stiffness make them 

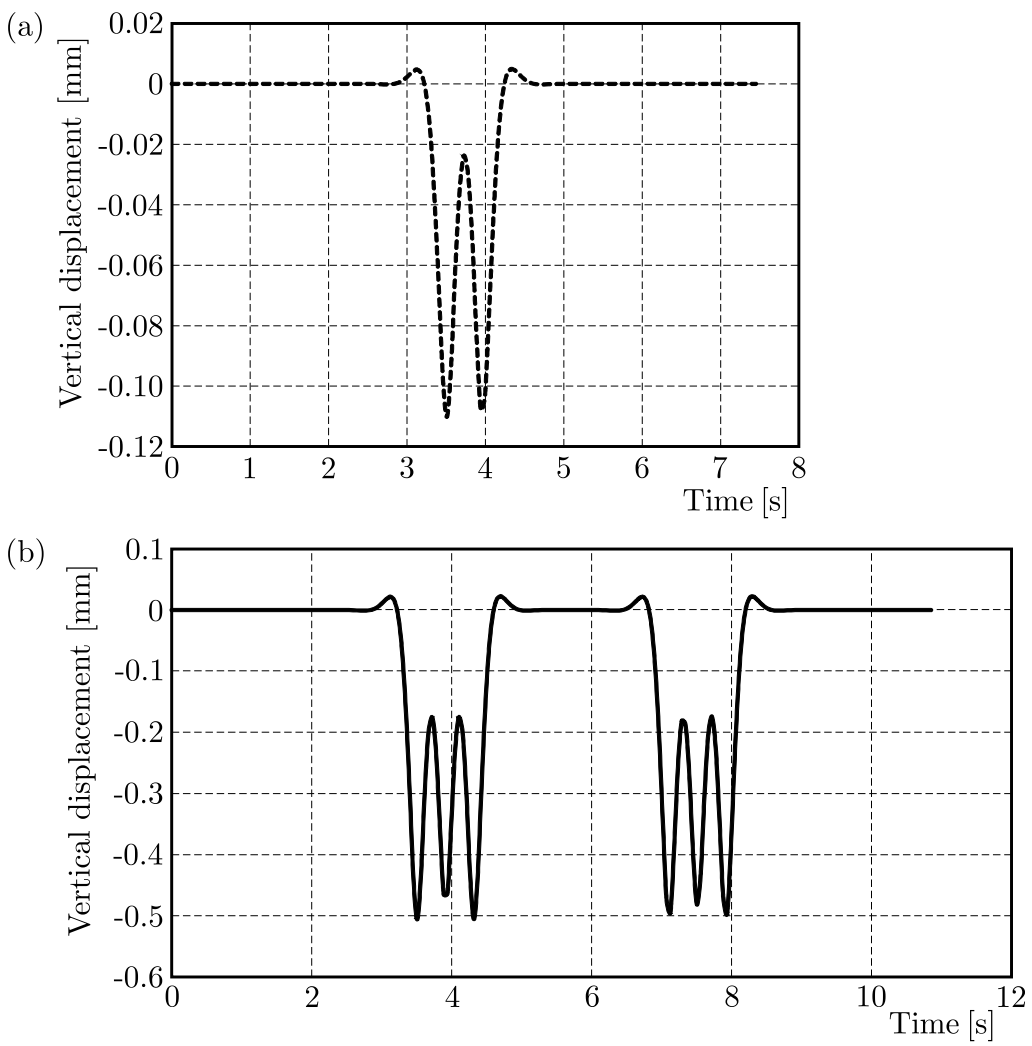

Fig. 8. Vertical displacement time history of ballasted railway track; (a) passing of a light draisine, (b) passing of heavy car body

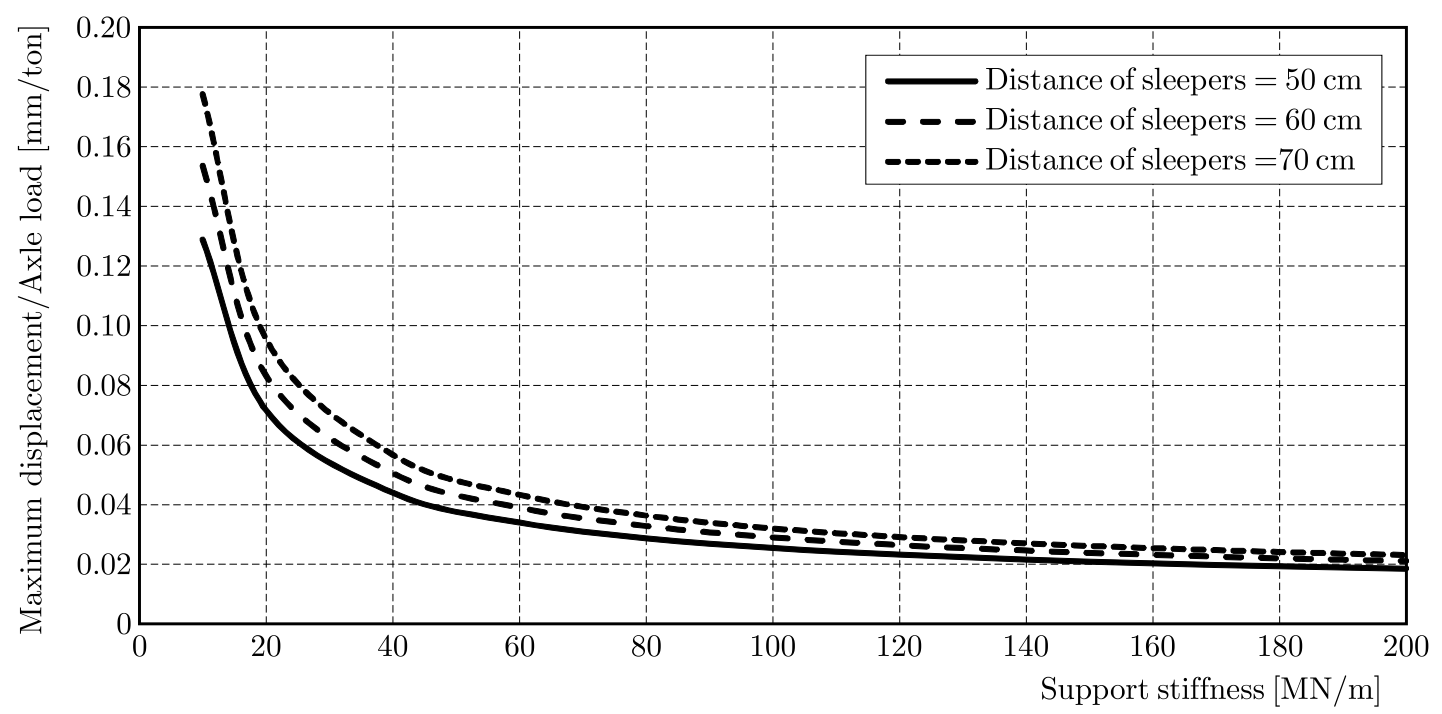

Fig. 9. Ratio of the maximum vertical displacement with respect to light and heavy axle loads versus the support stiffness

greater. The effect of the sleeper distance is significant as it decreases the support stiffness. The trend observed in Fig. 9 is close to the power equation as $y=a x^{b}$. The corresponding equations are presented in Table 1.

Table 1 indicates that the coefficients of the equations increase with the increasing distance of the sleepers. 
Table 1. Equations of the maximum vertical displacement per unit axle load against the support stiffness

\begin{tabular}{|c|c|c|}
\hline Distance of sleepers & Equations & $R$-Squared \\
\hline \hline $50 \mathrm{~cm}$ & $y=0.5 x^{-0.63}$ & $R^{2}=0.98$ \\
\hline $60 \mathrm{~cm}$ & $y=0.6 x^{-0.64}$ & $R^{2}=0.98$ \\
\hline $70 \mathrm{~cm}$ & $y=0.73 x^{-0.66}$ & $R^{2}=0.98$ \\
\hline
\end{tabular}

${ }^{*} x$ and $y$ are the support stiffness $[\mathrm{MN} / \mathrm{m}]$ and the maximum vertical displacement per unit load $[\mathrm{mm} / \mathrm{ton}]$, respectively

\section{Track behavior versus axle loads}

In the previous Section it has been shown that by increasing axle loads, the track behavior may be stabilised by increasing the support stiffness. Figure 10 indicates the maximum vertical displacement $[\mathrm{mm}]$ versus the axle load [ton] for various distances between the sleepers.

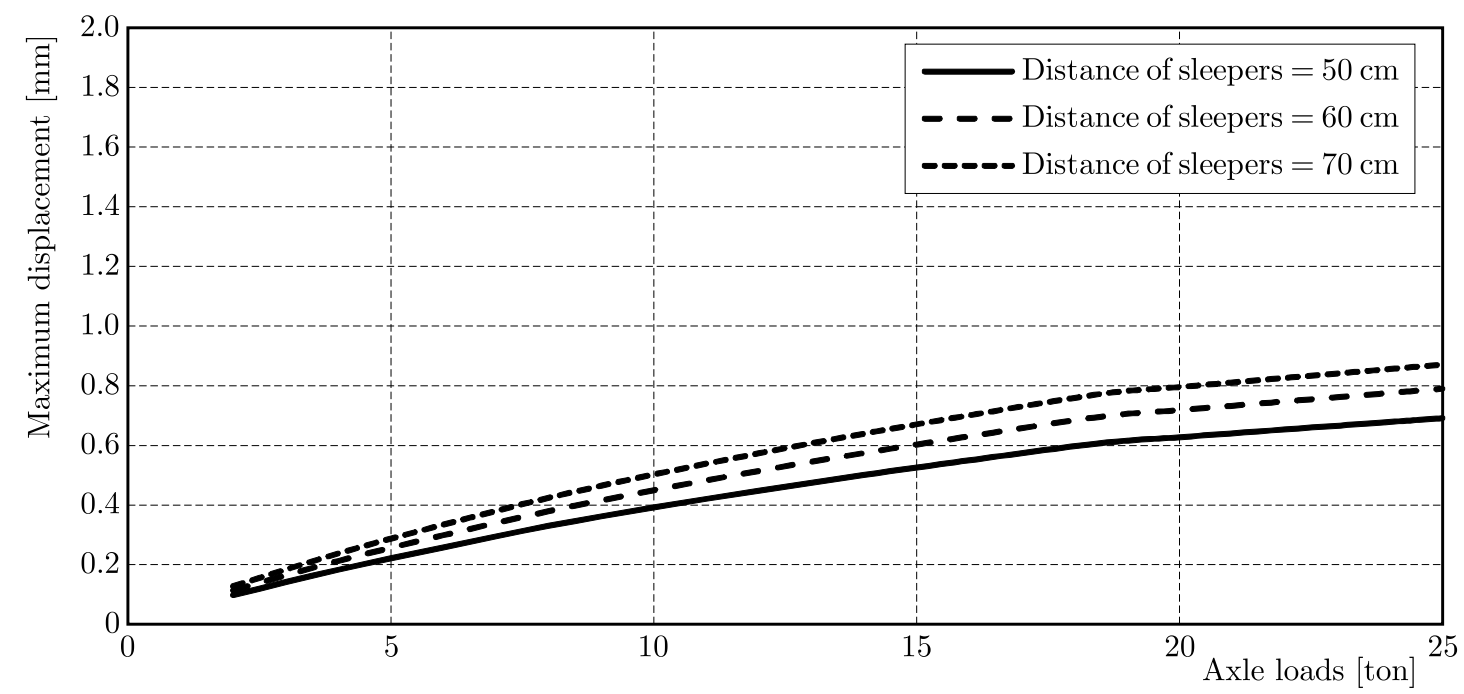

Fig. 10. The maximum vertical displacement for light and heavy axle loads

As can be observed is Fig. 10, the maximum vertical displacements increase with an increase in the axle loads. Also, they grow for greater sleeper distances. The effect of the sleeper distance is significant as it increases the values of axle loads. The trend of the diagrams is close to a logarithmic equation $y=a \ln (x)+b$. The corresponding equations are given in Table 2 .

Table 2. Equations for the maximum vertical displacement versus axle loads

\begin{tabular}{|c|c|c|}
\hline Distance of sleepers & Equations & $R$-Squared \\
\hline \hline $50 \mathrm{~cm}$ & $y=0.25 \ln (x)-0.15$ & $R^{2}=0.97$ \\
\hline $60 \mathrm{~cm}$ & $y=0.29 \ln (x)-0.17$ & $R^{2}=0.97$ \\
\hline $70 \mathrm{~cm}$ & $y=0.32 \ln (x)-0.18$ & $R^{2}=0.97$ \\
\hline
\end{tabular}

* $x$ and $y$ are axle loads [ton] and the maximum vertical displacement [mm], respectively

In Table 2, the coefficients of the equations increase with the distance between the sleepers. 


\section{Conclusion}

A review of technical literature indicates that the behavior of track supports is nonlinear and depends on train loads. For this reason, the effects of passing light and heavy railway vehicles have been studied in this paper. So, the simulation procedure of light and heavy car bodies has been explained. Afterward, results of a series of field tests with two light and heavy loadings have been presented for validating the numerical analyses. After validation, the effects of axle loads of light and heavy railway vehicles as well as support stiffness have been studied. The important findings of the present study can be summarized as follows:

- The range of the field responses is in a good agreement with the values of numerical analyses. Also, the trend of field responses is in a good agreement with the numerical analyses.

- By increasing the distance between the sleepers from 50 to $70 \mathrm{~cm}$, the ratio of the maximum vertical displacement with respect to the axle load increased by 33 and 25 percent at the support stiffness of 20 and $120 \mathrm{MN} / \mathrm{m}$, respectively.

- For the sleeper spacing $60 \mathrm{~cm}$, the ratio of the maximum vertical displacement with respect to the axle load decreased by 68 percent due to increasing of the support stiffness from 20 to $120 \mathrm{MN} / \mathrm{m}$.

- The trend of the ratio of the maximum vertical displacement with respect to the axle load against the support stiffness is close to a power equation $y=a x^{b}$. The coefficient $a$ in this equation is $0.5,0.6$ and 0.73 for the distance of between sleepers of 50,60 and $70 \mathrm{~cm}$, respectively. Correspondingly, the coefficient $b$ is $-0.63,-0.64$ and -0.66 , respectively.

- By increasing the axle loads from 8 to 18.5 tons, the maximum vertical displacement increased the 83 percent for sleeper spacing $60 \mathrm{~cm}$.

- By increasing the distance between the sleepers from 50 to $70 \mathrm{~cm}$, the maximum vertical displacement increased by 30 and 27 percent at the axle loads of 2 and 20 tons, respectively.

- The trend of the maximum vertical displacement against the axle loads is close to a logarithmic equation $y=a \ln (x)+b$. The coefficient $a$ in this equation is $0.25,0.29$ and 0.32 for the distance between the sleepers 50,60 and $70 \mathrm{~cm}$, respectively. Correspondingly, the coefficient $b$ is $-0.15,-0.17$ and -0.18 , respectively.

\section{Acknowledgment}

The authors are grateful to dr. S. Mohammadzadeh for his help in this study. The authors would like to thank technical engineers, R. Abbasi, M. Mehrali and M. Nouri, for their assistance during the course of this project.

\section{References}

1. Bogacz R., Czyczuła W., 2008, Response of beam on visco-elastic foundation to moving distributed load, Journal of Theoretical and Applied Mechanics, 46, 4, 763-775

2. CAI Z., 1992, Modeling of rail track dynamics and wheel rail interaction, PhD Thesis, Department of Civil Engineering, Queen's University, Kingston, Ontario, Canada

3. DahlBerg T., 2010, Railway track stiffness variations - consequences and countermeasures, International Journal of Civil Engineering, 8, 1, 1-12

4. Esmaeili M., Zakeri J.A., Mosayebi S.A., 2014, Effect of sand-fouled ballast on train-induced vibration, International Journal of Pavement Engineering, 15, 7, 635-644

5. Fryba L., 1999, Vibrations of Solids and Structures under Moving Loads, English co-edition published by Thomas Telford 
6. KerR A.D., 2003, Fundamentals of Railway Track Engineering, Simmons-Boardman Books, Inc.

7. Knothe K., 1995, Past and future of vehicle/track interaction, Vehicle System Dynamics, 24, 3-6

8. Popp K., Kaiser I., Kruse H., 2003, System dynamics of railway vehicles and track, Archive of Applied Mechanics, 72, 949-961

9. Puzavac L., Popovic Z., Lazarevic L., 2012, Influence of track stiffness on track behavior under vertical load, Scientific Journal on Traffic and Transportation Research, 24, 5, 405-412

10. Witt S., 2008, The Influence of Under Sleeper Pads on Railway Track Dynamics, Department of Management and Engineering, Division of Solid Mechanics, Linköping University, Sweden

11. ZAKeri J.A., 2000, Computer simulation for dynamics of railway track structures, PhD Thesis, School of Civil Engineering, Beijing Jiaotong University, Beijing

12. ZAKeri J.A., ABBAsi R., 2012, Field investigation of variation of rail support modulus in ballasted railway track, Latin American Journal of Solids and Structures, 9, 6, 643-656

13. Zakeri J.A., Ghorbani V., 2011, Investigation on dynamic behavior of railway track in transition zone, Journal of Mechanical Science and Technology, 25, 2, 287-292

14. ZAKeri J.A., XiA H., 2008, Sensitivity analysis of track parameters in train-track interaction, Journal of Mechanical Science and Technology, 22, 7, 1299-1304

15. Zhai W.M., Cai Z., 1997, Dynamic interaction between a lumped mass vehicle and a discretely supported continuous rail track, Computers and Structures, 63, 5, 987-997

16. Zhai W.M., Sun X., 1994, A detailed model for investigating vertical interaction between railway vehicle and track, Vehicle System Dynamics, 23, 1, 603-615

17. Zhai W.M., WANG K.Y., Lin J.H., 2004, Modelling and experiment of railway ballast vibrations, Journal of Sound and Vibration, 270, 4/5, 673-683 